\title{
Physical Activity Experiences of People with Multiple Sclerosis during the COVID-19 Pandemic
}

\author{
Alanna Koopmans and Chelsea Pelletier *(D) \\ School of Health Sciences, University of Northern British Columbia, 3333 University Way, Prince George, \\ BC V2N 4Z9, Canada; akoop99@student.ubc.ca \\ * Correspondence: chelsea.pelletier@unbc.ca
}

check for updates

Citation: Koopmans, A.; Pelletier, C. Physical Activity Experiences of People with Multiple Sclerosis during the COVID-19 Pandemic. Disabilities 2022, 2, 41-55. https://doi.org/ 10.3390/disabilities2010004

Academic Editor: Pantelis T. Nikolaidis

Received: 1 December 2021 Accepted: 4 January 2022

Published: 10 January 2022

Publisher's Note: MDPI stays neutral with regard to jurisdictional claims in published maps and institutional affiliations.

Copyright: (C) 2022 by the authors. Licensee MDPI, Basel, Switzerland. This article is an open access article distributed under the terms and conditions of the Creative Commons Attribution (CC BY) license (https:// creativecommons.org/licenses/by/ $4.0 /)$.

\begin{abstract}
During the COVID-19 pandemic, government and health officials introduced measures such as social distancing and facility closures that amplified barriers to physical activity. Certain groups, including people with multiple sclerosis (MS), have been underserved during the pandemic. In this qualitative study we aimed to: (1) explore the physical activity experiences of people with MS during the COVID-19 pandemic; (2) identify the facilitators and barriers to physical activity during COVID-19 for people with MS; and (3) make recommendations for inclusive physical activity policy and programming. We conducted semi-structured interviews with 11 adults (9 women) with MS during January and February 2021. Following an inductive thematic analysis, three themes were developed: (1) changing opportunities and adapting to new opportunities; (2) social isolation and physical activity; and (3) adapting physical activity to stay safe from COVID-19. Common facilitators identified included having knowledge and resources to adapt activities, social connections, and access to outdoor recreation opportunities. Identified barriers included fear and anxiety related to the spread of the virus, a loss of in-person activity options, and the closure of physical activity spaces. Online and at-home opportunities for physical activity were a valued and accessible way to address barriers to physical activity for people with MS, and should be maintained post-pandemic while considering flexibility to accommodate variable support needs.
\end{abstract}

Keywords: physical activity; exercise; physical disabilities; multiple sclerosis; qualitative; COVID-19; barriers; facilitators; social ecological model

\section{Introduction \\ 1.1. Multiple Sclerosis}

Multiple sclerosis (MS) is a chronic autoimmune disease affecting the central nervous system. Symptoms of MS vary by individual, disease type and progression, but common symptoms include vision impairment, loss of coordination and motor function, sensory disturbances, psychological impairment, cognitive impairment, and paralysis [1,2]. People with MS score clinically significantly worse than the general population on measures of fatigue, pain inference, general well-being, and quality of life $[3,4]$.

\subsection{Multiple Sclerosis E COVID-19}

The novel coronavirus (COVID-19) was declared a global pandemic in March 2020 by the World Health Organization [5]. During the period following this declaration, public health officials around the world imposed public health measures to mitigate the spread of the virus [6]. COVID-19 has been particularly challenging for certain groups of the population, including older adults and individuals living with chronic conditions or disability. The COVID-19 pandemic has added additional uncertainties and challenges to everyday life for people living with MS, including heightened levels of anxiety, mental distress, and stress [7-9]. The health impacts of COVID-19 for people with MS are both directly related to the spread of the virus and disruptions to daily life, and indirectly related 
to these through reduced access to healthcare and increased social isolation, subsequently widening health inequities for people with disabilities. Due to the nature of MS as an immune-mediated disease, as well as the nature of common disease modifying therapies, people with MS have an increased risk of opportunistic infection [10]. Although emerging evidence suggests that people with MS do not experience COVID-19 at rates greater than the general population [11,12], the unknown risk contributed to increased anxiety, depression, and fatigue among people with MS compared to the general population $[13,14]$. Many people with MS reported apprehension about maintaining their disease-modifying treatments and seeking health care services during the COVID-19 pandemic [13,15].

\subsection{Multiple Sclerosis \& Physical Activity}

People with MS identify physical activity as a self-management tool with psychological and physical benefits [16]. Physical activity is a potential disease-modifying strategy for people with MS that can improve aspects of symptom severity and fatigue management $[17,18]$. The benefits of physical activity for people with MS include improvements in symptoms of fatigue, pain, and depressive symptoms, as well as improvements in walking, balance, and muscle strength $[17,18]$. People with MS face a myriad of barriers to physical activity related to disease progression and symptoms (e.g., fatigue, physical disability), lack of social support, safety concerns, and accessibility [16,18-20]. Commonly reported facilitators of physical activity for people with MS include fatigue management, peer support, and social connectedness $[16,21]$. It is unknown how the risks of contracting COVID-19 compound the burden of maintaining health and wellness lifestyle habits for people with MS, or how policy makers and physical activity service providers can support inclusive programming during the pandemic and through recovery.

\subsubsection{Social Ecological Model}

The social ecological model describes behavior as influenced at the levels of the individual, social environment, physical environment, and policy. The individual level includes socio-demographic characteristics as well as social cognitions, attitudes, and skills [22-24]. Social environment includes interactions in social networks, social supports, and work environments [22-24]. The physical environment considers natural and built environments [22-24], while the policy level considers the laws and regulations at the local, provincial, and national levels that impact opportunities for physical activity [22-24]. The social ecological model is well suited to conceptualize engagement in physical activity for persons with disabilities, including barriers and facilitators, by considering how environmental factors impact accessibility and interact with personal factors to alter opportunities [22,25]. The interaction between barriers at the various levels of the social ecological model contribute to low physical activity levels among people with MS and other physical disabilities [26,27]. It is critical to understand the dynamic and interconnected social ecological barriers and facilitators to physical activity for people with MS to develop and adapt health promotion efforts.

\subsubsection{Multiple Sclerosis \& Physical Activity during COVID-19}

COVID-19 pandemic restrictions included full or partial closures of areas where physical activity is commonly performed, such as recreation facilities, parks, and playgrounds [28]. These facility closures, as well as anxiety related to the spread of the virus, impacted the movement behaviors (e.g., physical activity and sedentary behavior) of people with MS, including a reduced daily step count and nearly $20 \%$ of survey participants stopping activity altogether during pandemic lockdowns $[29,30]$. Many studies have examined how people with disabilities have experienced the COVID-19 pandemic and identified a disproportionate burden on mental health [13,31], but fewer have examined lived experiences specific to people with MS, and how the unique disease progression associated with MS, physical disability, and COVID-19 intersect to impact physical activity behavior. 
As argued by Learmonth and Motl [19], stories and experiences captured through qualitative evidence are needed to supplement quantitative data: "qualitative inquiry provides an opportunity for extending our knowledge of [phenomena of one's choosing] beyond the limitations of items on numerical scales and focal scientific outcomes by telling us, in the person's own words". Qualitative methods during times of epidemics are particularly important for vulnerable groups, such as people with MS or other chronic conditions, as these methods add insights related to needs, values, and understanding behavior beyond epidemiological modeling by giving a voice to those who have been underserved [32].

Using a qualitative approach framed by the social ecological model, the aim of this study was to describe the experiences of physical activity for people with MS during the COVID-19 pandemic and identify barriers and facilitators to physical activity behavior. A secondary aim was to use lived experiences to inform future practice and develop strategies to support inclusive physical activity opportunities for people with MS.

\section{Materials and Methods}

\subsection{Participants $\mathcal{E}$ Recruitment}

Using purposive and snowball sampling [33], participants were recruited using a poster uploaded to targeted social media groups and the MS Society of Canada's Research Portal. To reduce the compounding influence of aging, disability, and perceptions of COVID-19 risk, participants were required to be between the ages of 18-65. Other inclusion criteria included living in British Columbia, Canada, the ability to speak and comprehend English at a level sufficient to participate in an interview, and self-identity as a person with MS. Interviews were conducted during the months of January and February 2021, when the provincial COVID-19 restrictions on social gatherings introduced in November 2020 had been in place for several months. The study methods, including data collection and analysis, were reviewed and approved by the University of Northern British Columbia Research Ethics Board (E2020.1117.054). All participants provided written or verbal informed consent.

\subsection{Data Generation}

Data was collected through semi-structured interviews (see Table 1 for example questions) and a brief demographic questionnaire. The interview guide was developed to query experiences of physical activity before and during the pandemic, barriers and facilitators to engagement during COVID-19, and to identify support needs. Interviews were approximately 45 min long, conducted by AK via Zoom or telephone, audio recorded, and transcribed verbatim. Each participant was assigned a pseudonym using a random name generator. Field notes were taken at the end of each interview and were used to provide contextual information during data analysis. Participants who wished to review their transcript $(n=5)$ were sent the transcribed interview by email. No participants requested changes to their transcripts or made additional reflections or additions to their data.

Table 1. Examples of semi-structured interview questions.

\begin{tabular}{ll}
\hline \multicolumn{1}{c}{ Topic } & \multicolumn{1}{c}{ Example Interview Questions } \\
\hline & $\rightarrow$ What does physical activity mean to you? \\
$\begin{array}{ll}\text { Physical activity experiences } \\
\text { during COVID-19 }\end{array}$ & $\rightarrow$ What motivates you to be physically active? \\
& $\rightarrow$ In what ways has your physical activity changed during the \\
& pandemic?
\end{tabular}




\subsection{Data Analysis}

Data were analyzed using inductive and deductive reflexive thematic analysis, as described by Braun and Clarke [34]. Reflexive thematic analysis was chosen because it supports the identification of patterns of lived experience to advance the understanding of complex phenomena, is flexible regarding different orientations and approaches (e.g., inductive and deductive), and supports policy and practice-oriented research [34-36]. The researchers came to this study as residents of northern British Columbia, as women, and as able-bodied individuals with experience of interacting with individuals who live with MS or care partners of individuals who live with MS.

Inductive analysis was used to develop codes and themes to describe the physical activity experiences of individuals with MS during COVID-19. Data analysis was completed through six iterative phases by AK:

- Familiarization involved getting to know the dataset through the transcription of interview audio files, reading and re-reading transcripts, and taking initial notes of ideas of interest to answer the research questions.

- Generating initial codes consisted of identifying and labelling points of interest and relevance in the dataset as the first step in organizing data into meaningful groups. This was done through a combination of highlighting, cutting, and pasting pieces of interviews into charts and tables through multiple rounds of reading and re-reading the transcripts.

- Initial themes were developed by grouping coded and collated data into broader categories using charts and tables to capture the shared meaning. Sub-themes were developed where necessary to identify a distinct pattern within a theme.

- Reviewing and refining themes. Through critical discussions, analytical reflection, and returning to sections of the dataset, themes were refined to ensure they appropriately answered the research questions, reflected the lived experience of participants, and included a central organizing concept with a distinct definition.

- Defining and naming themes, where the main ideas were determined, appropriately named to reflect experiences and answer the research questions, and data extracts (e.g., quotes) exemplifying these ideas were identified.

- Writing involved collating developed themes, definitions, and stories captured within the dataset through a written narrative with data extracts to illustrate themes.

Deductive analysis was used to identify the facilitators and barriers to physical activity based on the social ecological model [22,24]. Similar to the first step outlined above, AK familiarized themselves with the data by reading and re-reading the interview transcripts and taking notes specially related to alignment of the dataset with the social ecological model. Following familiarization, AK highlighted and underlined parts of the transcripts that answered the following research question: "What are the facilitators and barriers to physical activity during the COVID-19 pandemic for people with MS?" Tables were used to categorize the various facilitators and barriers according to the four levels of the social ecological model: (1) Individual; (2) Social Environment; (3) Physical Environment; and (4) Policy.

\subsection{Rigor}

Throughout the analysis process, the lead author (AK) engaged in reflexive journaling and regular meetings with the senior author $(\mathrm{CP})$ and peers to discuss processes and review analytical engagement with the data. The discussion of the codes and themes being generated with 'critical friends' allowed for reflection, reflexivity, suggestion of different ways of interpreting the data, and critical feedback on processes $[37,38]$.

\section{Results}

Eleven interviews were conducted. Participants self-identified as being diagnosed with MS for an average of 15.5 years (range: 1-26 years; Table 2 ). The mean age ( \pm SD) of 
participants was $45.1 \pm 11.9$ years and the majority $(n=9)$ identified as women. The use of mobility aids varied; $45.5 \%$ of participants did not use a mobility aid of any kind.

Table 2. Demographic information of participants.

\begin{tabular}{ll}
\hline \multicolumn{1}{c}{ Characteristic } & \multicolumn{1}{c}{ Participant Responses } \\
\hline \multirow{2}{*}{ Age range $(n, \%)$} & $18-33(2,18.2 \%)$ \\
& $34-49(5,45.5 \%)$ \\
& $50-64(4,36.4 \%)$ \\
\hline \multirow{2}{*}{ Gender $(n, \%)$} & Woman $(9,81.9 \%)$ \\
& Man $(2,18.2 \%)$ \\
Community size $(n, \%){ }^{1}$ & Rural $(1,9.1 \%)$ \\
& Small population center $(2,18.2 \%)$ \\
& Medium population center $(5,45.5 \%)$ \\
Type of MS $(n, \%)$ & Large population center $(3,27.3 \%)$ \\
\hline & No type identified $(1,9.1 \%)$ \\
& Relapsing remitting $(6,54.5 \%)$ \\
& Secondary progressive $(4,36.4 \%)$ \\
Years living with MS $(n, \%)$ & Unknown $(1,10 \%)$ \\
& $1-5(3,30 \%)$ \\
& $6-10(1,10 \%)$ \\
& $11-15(0,0 \%)$ \\
& $16-20(1,10 \%)$ \\
& $21-26(5,50 \%)$ \\
\hline & No mobility aid $(5,45.5 \%)$ \\
& Cane, walker, poles or other $(4,36.4 \%)$ \\
\hline & Motorized wheelchair or scooter $(2,18.2 \%)$ \\
\hline
\end{tabular}

${ }^{1}$ Population centers classification from Statistics Canada. Rural area-territory outside population center; Small population center-population of 1000-29,999; medium population center-population 30,000-99,999; large population center-population 100,000 or more.

\subsection{Experiences of Physical Activity during the COVID-19 Pandemic}

Based on the physical activity experiences of people with MS during COVID-19, three themes were developed (Table 3): (1) changing opportunities and adapting to new opportunities; (2) social isolation and physical activity; and (3) adapting physical activity to stay safe from COVID-19.

Table 3. Themes and subthemes describing the physical activity experiences of people with multiple sclerosis during the COVID-19 pandemic.

\begin{tabular}{lll}
\hline \multicolumn{1}{c}{ Theme } & \multicolumn{1}{c}{ Definition } & \multicolumn{1}{c}{ Subthemes } \\
\hline $\begin{array}{l}\text { Changing opportunities and adapting } \\
\text { to new opportunities }\end{array}$ & $\begin{array}{l}\text { Participants responded to the challenges associated } \\
\text { with physical activity during COVID-19 through } \\
\text { creative means and adaptation of activities they did } \\
\text { pre-pandemic. }\end{array}$ & $\begin{array}{l}\rightarrow \text { Creativity and adaption } \\
\text { physical activity } \\
\text { phentits to new ways of doing } \\
\text { doing physical activity }\end{array}$ \\
\hline Social isolation and physical activity & $\begin{array}{l}\text { Physical activity is an opportunity to engage with } \\
\text { others and remained so during the COVID-19 } \\
\text { pandemic. Social engagement can be a motivating } \\
\text { reason to be physically active. }\end{array}$ & $\rightarrow$ Physical activity connects us \\
\hline $\begin{array}{l}\text { Adapting physical activity to stay } \\
\text { safe from COVID-19 }\end{array}$ & $\begin{array}{l}\text { Participants took precautionary measures to keep } \\
\text { themselves and their families safe from COVID-19; } \\
\text { this involved what kinds of physical activity they } \\
\text { engaged in, and how. }\end{array}$ & $\rightarrow$ Concerns and caution \\
\hline
\end{tabular}




\subsubsection{Changing Opportunities and Adapting to New Opportunities}

COVID-19 imposed new challenges on physical activity for people with MS. The routines and activities of participants were put on hold, as they and those around them adapted to the new, socially distanced world. Daniela discussed the loss of being able to go to the gym:

"It's kind of just losing the routine and then trying to get back to, ok, how am I going to do this now? Like you're used to going to the gym 2 to 3 times a week uh doing your routine at the gym and when you lose that, because our gym closed."

Creativity \& Adaption

Participants used their homes and nearby outdoor spaces to stay active during COVID19. They were resourceful in finding and using equipment they had already and learned new activities or made modifications to their homes to provide additional space for movement. Christiane converted a room in their house to be more conducive for physical activity:

"I have set up my home room differently, so I don't know if you can see, but behind me are some mirrored doors. I've changed it so when I'm live streaming I can still be looking in the mirror to see what my form is like while I've got the instructor over my back. To more simulate what we were doing in the dance studio."

Several participants purchased or had plans to purchase new equipment like snowshoes, skis, and bikes, as described by Claire:

"I actually bought snowshoes this year too, so, I go snowshoeing too, not just walking, I guess. Yeah. That's totally new this year."

Utilizing online fitness classes was another way in which participants remained active. Briana, a long-time attendee of an in-person bootcamp, explained how their fitness instructor adapted programming during COVID-19:

"For years I went to a bootcamp in town and now I do it at home using it online. He has become an online bootcamp instructor to serve those of us who can't come in."

Benefits to New Ways of Doing Physical Activity

Despite the additional barriers, individuals reported some positive experiences with physical activity during COVID-19. There was recognition by Gabriela of some of the advantages online physical activity delivery provided for people in terms of accessibility:

"[i] $t$ doesn't matter where you live or what you have available, you can be part of a class, a group and all be receiving the same benefits."

Christiane explained how the online delivery provided flexibility to complete activity at their own pace:

"I do like the fact that we get on, it's sort of a 45-min to an hour, two days a week it's 45-min and on Fridays it's an hour-long class. Um, what I like is it's time, you get it done, there's no travelling time, there's no whatever, so, um, if I'm tired afterwards or if I need to take a break, um, I just turn my video off. I take my break. So that's, that's better for me and my MS. Where in the studio, you're going, oh everybody's watching."

Some individuals took up new activities they hope to continue once the pandemic is resolved. For example, Daniela hoped to continue working out at home as they appreciated the convenience:

"I personally would love to continue to work out at home because it's proven its benefits and like having a busy school schedule, like and just being able to work out when it's convenient that's been super beneficial." 
Drawbacks of New Ways of Doing Physical Activity

Many participants voiced the positive experiences they had with online, at home, or outdoor physical activity during COVID-19, but there were also some drawbacks discussed, such as loss of social connection and unpredictability. Christiane recognized the impact the loss of a biking group had on their daily routine:

"And now, like this morning we didn't go out until 11:15 or so because we are not all part of a group. There are some drawbacks to that, for example today not going until 11:15, not getting back until 1:00 after a good 30 kilometres, then I come home, I'm tired and I find I'm less motivated to do anything in the afternoon. I'm not doing as many different things, where I guess I think pre-COVID I was a better balancer at my time management."

Online activity classes also presented challenges for participants, such as distractions and the absence of others around you. The loss of in-person social connection during physical activity was mentioned by several participants. Briana described how they missed group activity:

"Not having other people there. Like sometimes the vibe when everybody gets working out together, it pushes you, makes you work out harder. Sometimes when you're by yourself nobody is telling you to you know, hold that longer or to tighten up or you know. I miss that."

\subsubsection{Social Isolation \& Physical Activity}

Nearly every participant touched on the isolation that has resulted from COVID-19. Briana articulated their experience with:

"I mean during the summer there were weeks that I went without seeing anyone except my husband. That would be the biggest thing is the isolation. That I do things. I do so many things alone now."

Physical Activity Connects Us

Due to COVID-19, participants reduced their social networks, and physical activity remained an important opportunity to safely connect with others. Participants maintained connections with friends or family through outdoor or online activity, which helped them during this time, as Claire described:

"Because staying at home drives me crazy. Like I can't do that. Actually, it causes worse depression for MS being at home all day. Except for walking with [friend's name]. We go for long walks with dogs or whatever. Like kilometers."

Even walking alone offered an opportunity for participants to connect with other people, even if it was only an exchanged greeting with people as they walked past. Lita said:

"[A] lot of the people that I see on those walks I start seeing daily and they just start saying hi, how are you. You get to know them a little bit. Again, it's nice for me, somebody who's a homebody, who doesn't get to see people all the time, right. It's just that nice interaction for someone who literally doesn't get that all day long."

\subsubsection{Adapting Physical Activity to Stay Safe from COVID-19}

Participants took precautionary measures to keep themselves and their families safe; this involved what kinds of physical activity they would engage in, and how they did so.

\section{Concerns \& Caution}

Several participants explained that they stopped going to the gym, as they did not think it was a safe space to be during the time of the pandemic. Daniela expressed their anxieties about the virus, especially given their own health status: 
"[I] t's definitely been terrifying because I am not only higher on the disability scale with MS, but I have taken LEMTRADA ${ }^{\circledR}$ which is a chemotherapy or an immunosuppressant."

Being in spaces where they were potentially exposed to the virus was a main concern for many participants, such as Natalia:

"And even going outside for walks and stuff in the beginning because COVID-19 is scary, because um living with a disease it's scarier."

Participants were not the only ones with concerns; participants' family members were also concerned about the safety of their loved ones. Briana's daughter made their concern clear and the participant responded accordingly:

"I'm very careful to make sure that anybody I come into contact with has an extremely small bubble. We wear masks or you know, I don't go into stores, I don't do anything like that, so, yeah each and every activity that I do I have to think about what's the consequence. Like, um, in the beginning and I was still kind of doing my life as normal. Until one of my daughters said, hey, I kind of like you to be around, so do you sort of think you can smarten up and isolate yourself."

Participants used caution when making decisions about physical activity. Briana went on to explain how their risk assessment changed during COVID-19:

"So, my risk assessment has changed, now it's not just: is there going to be a bear; are there going to be rocks; am I going to fall and hurt myself? You know, is weather going to come in? Now it's also, who are you going to come into contact with? Um, are you going to bring COVID home to your husband? Are you going to, you know?"

\subsection{Facilitators $\mathcal{E}$ Barriers of Physical Activity during the COVID-19 Pandemic}

Barriers to and facilitators of physical activity were identified in the interview transcripts and mapped to the social ecological mode (Tables 4 and 5).

Table 4. Facilitators of physical activity participation in people with multiple sclerosis during the COVID-19 pandemic analyzed deductively using the social ecological model.

\begin{tabular}{|c|c|c|}
\hline Level & Facilitators & Example Quotes \\
\hline Individual & $\begin{array}{l}\rightarrow \text { Feeling well and healthy } \\
\rightarrow \text { Knowledge that exercise is good for you } \\
\rightarrow \text { Self-awareness } \\
\rightarrow \text { Self-motivation } \\
\rightarrow \text { Having a goal or reason to exercise } \\
\rightarrow \text { Not wanting to stay at home all day } \\
\rightarrow \text { New equipment } \\
\rightarrow \text { Having the equipment already, such as internet connection, yoga } \\
\text { mats, weights, etc. } \\
\rightarrow \text { Fitness trackers } \\
\rightarrow \text { Prior knowledge of how to utilize things you have in the home to } \\
\text { be active } \\
\text { MS Specific: } \\
\rightarrow \text { When fewer symptoms present it is easier to be active } \\
\rightarrow \text { Being active improves MS symptoms } \\
\rightarrow \text { Desire to regain strength and mobility } \\
\rightarrow \text { Materials specifically for individuals with MS }\end{array}$ & $\begin{array}{l}\text { Diane: "And then, since being diagnosed, it's } \\
\text { like you know what, I can do this. Nobody's } \\
\text { going to tell me that I can't do something, and } \\
\text { I know I can do it." } \\
\text { Natalia: "I have a FitBit and seeing my } \\
\text { points, like the steps add up motivates me } \\
\text { more." } \\
\text { Christiane: "Where I already had my yoga } \\
\text { mat, all the types of things I needed to } \\
\text { transition to doing [physical activity] it at } \\
\text { home. So, I had the computer, I had the } \\
\text { high-speed internet. You know, all these types } \\
\text { of things that some other people might not } \\
\text { have had, I was fortunate to have." } \\
\text { Lita: "I've noticed that when my physical } \\
\text { activity, even in the slightest doing laps for } \\
\text { an hour or two, it helps me with my MS. It } \\
\text { makes me feel stronger, I'm gaining a little bit } \\
\text { more strength, I'm able to be a little more } \\
\text { energized than usual." }\end{array}$ \\
\hline
\end{tabular}


Table 4. Cont.

\begin{tabular}{|c|c|c|}
\hline Level & Facilitators & Example Quotes \\
\hline $\begin{array}{l}\text { Social } \\
\text { Environment }\end{array}$ & $\begin{array}{l}\rightarrow \text { People who encourage } \\
\rightarrow \text { Being a caregiver: motivation to move and care for children } \\
\rightarrow \text { Friend(s) to walk with in a small bubble } \\
\rightarrow \text { Need for social interaction } \\
\rightarrow \text { Family who help out with working out at home } \\
\rightarrow \text { Free online programming } \rightarrow \text { Shift of regular programming to } \\
\text { online programming } \\
\rightarrow \text { Fitness tracker with family and friends } \\
\rightarrow \text { Friends who have found good resources and have sent them } \\
\text { MS Specific: } \\
\rightarrow \text { Connections through support groups } \\
\rightarrow \text { Friends with MS who set an example of being active } \\
\rightarrow \text { Changing message about MS and PA: good for you } \\
\rightarrow \text { Having exercise providers that work with you to tailor exercise }\end{array}$ & $\begin{array}{l}\text { Lita: "They have been the biggest support } \\
\text { system. My friends have really been able to } \\
\text { help me get through and motivate me to do } \\
\text { those simple tasks or go for that walk, even } \\
\text { though I'm not feeling the best." } \\
\text { Briana: "going online has been critical } \\
\text { because if it wasn't that I wouldn't be doing } \\
\text { it. Um, that's probably the number one thing } \\
\text { that's helped me." }\end{array}$ \\
\hline $\begin{array}{l}\text { Physical } \\
\text { Environment }\end{array}$ & $\begin{array}{l}\rightarrow \text { Living in rural location: less likely to come into contact when } \\
\text { doing PA and being able to exercise outside } \\
\rightarrow \text { Not having to wear a mask when exercising outdoors } \\
\rightarrow \text { Milder winter, spring, and summer weather } \\
\rightarrow \text { Space to walk around and move inside the house } \\
\rightarrow \text { Making one's home more suited to PA (e.g., setting it up similar } \\
\text { to a studio) } \\
\rightarrow \text { Convenience of exercising at home }\end{array}$ & $\begin{array}{l}\text { Diane: "I think just being outside would } \\
\text { make the difference, being inside I don't think } \\
\text { I would be um, inclined to do as much } \\
\text { [physical activity] being outside you don't } \\
\text { need to wear a mask so that's kind of a cool } \\
\text { thing." } \\
\text { Briana: "Where I live there's no people, so I } \\
\text { can go exercise. I can hike, I can swim, I can } \\
\text { whatever, without coming into contact with } \\
\text { any other people." }\end{array}$ \\
\hline Policy & None identified & None identified \\
\hline
\end{tabular}

MS, multiple sclerosis; PA, physical activity.

Table 5. Barriers to physical activity participation in people with multiple sclerosis during the COVID-19 pandemic analyzed deductively using the social ecological model.

\begin{tabular}{|c|c|c|}
\hline Level & Barriers & Example Quotes \\
\hline Individual & $\begin{array}{l}\rightarrow \text { COVID-19 was a ready-made excuse } \\
\rightarrow \text { Fear of contracting COVID-19 } \\
\rightarrow \text { Lack of information about COVID-19 } \\
\text { MS Specific: } \\
\rightarrow \text { Temperature regulation } \\
\rightarrow \text { Limited and gradually decreasing mobility } \\
\rightarrow \text { Fatigue } \\
\rightarrow \text { Relapses } \\
\rightarrow \text { Lack of information about PA \& MS } \\
\rightarrow \text { Challenge to have the mental fortitude to continue to } \\
\text { engage with the world }\end{array}$ & $\begin{array}{l}\text { Viktor: "[COVID,] it's a ready-made excuse, as well for } \\
\text { people and we're all just kind of cocooning." } \\
\text { Daniela: "I had a relapse and I think that was like } \\
\text { another huge thing that threw a wrench into things, on } \\
\text { top of COVID-19." }\end{array}$ \\
\hline $\begin{array}{l}\text { Social } \\
\text { Environment }\end{array}$ & $\begin{array}{l}\rightarrow \text { Isolation } \\
\rightarrow \text { Loss of in person group PA } \\
\rightarrow \text { Walking/running alone } \\
\rightarrow \text { Interacting with people with larger bubbles } \\
\rightarrow \text { Online classes: limited capacity, more distractions, less } \\
\text { motivated } \\
\rightarrow \text { Shift to online appointments decreases time in } \\
\text { community } \\
\rightarrow \text { Stressful work environments }\end{array}$ & $\begin{array}{l}\text { Elinor: "I mean I've been home since you know for a } \\
\text { year now. I hardly go out. I go to the hospital to change } \\
\text { my catheter. I don't even go to the doctor because I talk } \\
\text { to the doctor on the phone." }\end{array}$ \\
\hline
\end{tabular}


Table 5. Cont.

\begin{tabular}{|c|c|c|}
\hline Level & Barriers & Example Quotes \\
\hline $\begin{array}{l}\text { Physical } \\
\text { Environment }\end{array}$ & $\begin{array}{l}\rightarrow \text { Accessibility of built environment } \\
\rightarrow \text { Cannot go to the place once gone to for exercise } \\
\rightarrow \text { Gyms not safe places during COVID-19 } \\
\rightarrow \text { Icy trails/sidewalks } \\
\rightarrow \text { Areas with steep hills } \\
\rightarrow \text { Lack of accessible sidewalks } \\
\rightarrow \text { Trails got very busy } \\
\rightarrow \text { Narrow trails don't allow for social distancing }\end{array}$ & $\begin{array}{l}\text { Gabriela: "it sounds so trivial, but from where the } \\
\text { change room is to the actual pool, it's an extremely long } \\
\text { walk for me and like where you have to place your towel. } \\
\text { It seems so trivial, but when you're living with } \\
\text { ambulation limitations it's huge. And so, for me that's } \\
\text { been, utilization of city services has been challenging." }\end{array}$ \\
\hline Policy & $\begin{array}{l}\rightarrow \text { Closure of pools \& gyms } \\
\rightarrow \text { Extra steps to access city services (e.g., booking in } \\
\text { advance or online) } \\
\rightarrow \text { Absence of services specially for people with MS } \\
\rightarrow \text { Lack of acknowledgement of the need for people with } \\
\text { physical disabilities to be able to access city services } \\
\rightarrow \text { Lack of leadership or direction/information }\end{array}$ & $\begin{array}{l}\text { Gabriela: "Trying to utilize city services, trying to } \\
\text { utilize the pool ... any of those areas has been an } \\
\text { utterly frustrating experience. I don't know how people } \\
\text { are actually able to book a time at the pool because they } \\
\text { are always full." }\end{array}$ \\
\hline
\end{tabular}

PA, physical activity; MS, multiple sclerosis.

\subsubsection{Individual}

Individual facilitators of physical activity participation expressed by participants included self-motivation, feeling well, controlling symptoms and having the knowledge and resources to be physically active. The inner drive and self-motivation to be active was repeated throughout multiple interviews. Having exercise equipment available at home and buying new equipment for different activities helped facilitate activity during COVID-19. There were several facilitators specific to MS mentioned, including having fewer symptoms, improvement of symptoms when one is physically active, the desire to regain strength and mobility, and having materials tailored specifically for individuals with MS.

Participants also experienced barriers to physical activity at the individual level, which included handling the fear and lack of information around COVID-19, and the ready-made excuse COVID-19 provided to skip physical activity. Some barriers to physical activity that were MS-specific centered around the effects of MS symptoms (i.e., fatigue, challenges with temperature regulation, decreased mobility, relapses). Relapses were cited by many as another obstacle to physical activity that they experienced over the past year.

\subsubsection{Social Environment}

Social environmental barriers revolved around the loss of social connections, feelings of isolation, the closure of group physical activity, stressful work environments, and challenges associated with online and at-home physical activity. Facilitators at the social environmental level during the COVID-19 pandemic included having a supportive social network (i.e., friends, family, other individuals with MS). Support took the form of encouragement, sharing of resources, professionals who helped tailor activities for participants' abilities, having others who set good examples of physical activity, and having friends to exercise with consistently. The shift of regular in-person programming to online programming during the pandemic was another important facilitator of physical activity for several participants.

\subsubsection{Physical Environment}

There were factors of the physical environment that helped participants remain active during COVID-19, including the options available for outdoor physical activity, a milder winter, exercising in more rural locations where one was less likely to interact with other individuals, and setting up one's house to accommodate indoor physical activity. Barriers at the physical environmental level included icy trails or sidewalks, and trails that were 
too narrow to allow for social distancing. Having enough space to stay safe was a major barrier, and places that individuals once used, such as the mall (to walk), a pool (to swim) and the gym (to work out) were deemed unsafe for participants.

\subsubsection{Policy}

There were no policy-level facilitators identified by participants, however, there were several barriers identified. These barriers included closures of pools and gyms, additional steps to access certain services (i.e., booking in advance for the pool), and a lack of leadership, support, and direction from leaders during COVID-19.

\section{Discussion}

This study is one of the first qualitative studies exploring physical activity experiences of people with MS during the COVID-19 pandemic. Physical activity experiences during COVID-19 were marked by creativity and adaption involving at-home activity, online classes, or getting outside where close-contact interaction was minimal. Creative and adaptive physical activity responses helped mitigate increased social isolation during the COVID-19 pandemic. Key facilitators identified were having the knowledge and resources to use things at home to be active, one or two friends who were in one's bubble to be active with, and the option of outdoor physical activity. Barriers were fear and anxiety around COVID-19, loss of in person group physical activity, and closures of physical activity spaces. The experiences of people with MS presented in this study may provide direction to communities, health professionals, exercise providers, care partners, and individuals with MS as they navigate physical activity practices, planning, and resource distribution in the wake of the COVID-19 pandemic.

Participants noted that their social connections had decreased when the pandemic began, and nearly a year into the pandemic, social interactions remained very limited. As a result of decreased social interactions, social isolation and loneliness have been experienced globally during the COVID-19 pandemic [39]. Past research has shown that people with MS experience social isolation, particularly individuals with more severe disabilities [40]. Participation (i.e., the involvement in life situations) restrictions have been identified in people with MS and increase with disability level [41,42]. Our findings highlight that physical activity is a way to maintain connections during COVID-19, although this was more of a challenge for individuals experiencing more severe disability. These findings can be applied to physical activity promotion for people with MS; knowing that individuals value the social nature of physical activity may direct the design, focus, or goals of future interventions involving physical activity.

Many participants found online and at-home activity a satisfactory way to remain active during the pandemic. As with a group of participants with MS living in Australia [43], the participants in our study noted increased engagement in outdoor recreation and activity options to manage risk, and demonstrated resilience in retaining aspects of their pre-COVID exercise routines and their health status. Participants enjoyed the flexibility, convenience, and safety that outdoor and online options provided. Several participants even hoped that online activity options would continue when COVID-19 has been resolved. Previous research has shown that using the internet is an effective way to deliver exercise interventions for people with MS [44]. Similar to previous work [45], the absence of social connection was highlighted as a drawback of home-based and web-based activities adopted during the pandemic. Web-based physical activity may be an excellent complement to in-person programming but cannot replace in-person physical activity altogether [46].

Facilitators of and barriers to physical activity were identified and coded according to the social ecological model (individual, social environment, physical environment, policy). In this study, some barriers were unique to the COVID-19 pandemic (i.e., fear around COVID-19, gym closures, etc.). However, most barriers to physical activity for people with MS identified in this study have been discussed in previous literature; these factors include fatigue, relapses, isolation, stress, inaccessible physical environments, and obstacles 
to access city services [19,46,47]. Many of the COVID-19-specific barriers identified in this study will likely be remedied naturally as health orders and COVID-19 conditions improve. Of greater importance for long-term health in people with MS is addressing and developing strategies for the barriers identified in this study that were relevant even prior to the COVID-19 pandemic, including physical accessibility, social exclusion, and lack of specific adapted programming.

\subsection{Limitations}

The participants recruited for this study may represent a more active subset of the population living with MS, as people with an interest in physical activity may have been more inclined to participate, although we did not include a measure of physical activity behavior. Additionally, the recruitment process may have favored individuals who are more connected within their community through peer groups or individuals who regularly use the internet. Thus, our sample may have included more active and socially connected people who may have different perceptions of activity and greater resilience (both personal and due to socioeconomic circumstances) in overcoming barriers compared to the general population of people with MS. Interviews were conducted during January and February 2021, reflecting a specific time period when COVID-related restrictions in British Columbia allowed for the opening of fitness and recreation facilities with an approved COVID-19 safety plan, although no group classes were permitted. A longitudinal assessment may better capture physical activity experiences as a result of health policy changes and personal risk perceptions.

\subsection{Recommendations for Practice}

Based on the experiences described by participants and the barriers and facilitators identified, we make the following recommendations for inclusive exercise programming and practice:

For Individuals with MS:

- If you are active, other people with MS may be encouraged by your motivation and experience; consider sharing your success with others

- Set achievable goals

- Seek out physical activity information and materials specifically for people living with MS from trusted sources

For health professions/exercise providers:

- Online options can be valuable opportunities for people who may not otherwise be able to participate in in-person physical activity (e.g., due to distance or other barriers), even after COVID-19 is resolved

- Incorporating social connection and encouraging social engagement as part of physical activity programming may improve adherence and enjoyment for participants with MS

- Individuals with MS appreciate professionals who are willing to work with them to tailor exercise to their ability; each person with MS experiences symptoms in a different way

- More widespread sharing of information is needed about physical activity, the benefits of physical activity, and how one can use things around you to be physical active without an exercise facility (e.g., at home, outside)

For cities/communities/policymakers:

- Improvements to the accessibility of built environments benefits everyone

- Making booking systems (i.e., the pool) straightforward and flexible

- Develop physical activity and recreation spaces that enable both socialization and physical activity. 


\section{Conclusions}

This study provides novel insights into the experiences of people with MS during the COVID-19 pandemic. Although some identified barriers to physical activity mirrored those of the general population, there were unique factors impacting physical activity experiences for people with MS during COVID-19, including the accessibility of facilities and virtual activity options, limited access to disease-specific information regarding virus susceptibility, and increased social isolation. Addressing the persistent barriers found at the levels of the individual, social environment, physical environment, and policy, with particular emphasis on enhancing or maintaining social connection, may lead to improvements in physical activity experiences for individuals with MS beyond COVID-19.

Author Contributions: Conceptualization, A.K. and C.P.; methodology, A.K. and C.P.; formal analysis, A.K.; writing — original draft preparation, A.K.; writing—review and editing, C.P. All authors have read and agreed to the published version of the manuscript.

Funding: This research received no external funding.

Institutional Review Board Statement: The study was conducted according to the guidelines of the Declaration of Helsinki, and approved by the Institutional Review Board of University of Northern British Columbia (E2020.1117.054, 11 December 2020).

Informed Consent Statement: Informed consent was obtained from all participants involved in the study.

Data Availability Statement: The data presented in this study are not available due to privacy concerns.

Conflicts of Interest: The authors declare no conflict of interest.

\section{References}

1. Kister, I.; Bacon, T.E.; Chamot, E.; Salter, A.R.; Cutter, G.R.; Kalina, J.T.; Herbert, J. Natural history of multiple sclerosis symptoms. Int. J. MS Care 2013, 15, 146-156. [CrossRef]

2. Steinman, L. Multiple sclerosis: A two-stage disease. Nat. Immunol. 2001, 2, 762-764. [CrossRef] [PubMed]

3. Amtmann, D.; Bamer, A.M.; Kim, J.; Chung, H.; Salem, R. People with multiple sclerosis report significantly worse symptoms and health related quality of life than the US general population as measured by PROMIS and NeuroQoL outcome measures. Disabil. Health J. 2018, 11, 99-107. [CrossRef]

4. Bass, A.D.; Van Wijmeersch, B.; Mayer, L.; Mäurer, M.; Boster, A.; Mandel, M.; Mitchell, C.; Sharrock, K.; Singer, B. Effect of multiple sclerosis on daily activities, emotional well-being, and relationships: The global vsMS Survey. Int. J. MS Care 2020, 22, 158-164. [CrossRef] [PubMed]

5. WHO Director-General's Opening Remarks at the Media Briefing on COVID-19-11 March 2020. Available online: https:/ / www.who.int/director-general/speeches/detail/who-director-general-s-opening-remarks-at-the-media-briefing-oncovid-19---11-march-2020 (accessed on 22 December 2021).

6. Taylor, D.B. A Timeline of the Coronavirus Pandemic. The New York Times, 17 March 2021. Available online: https://www. nytimes.com/article/coronavirus-timeline.html(accessed on 22 December 2021).

7. Motl, R.; Ehde, D.; Shinto, L.; Fernhall, B.; LaRocca, N.; Zackowski, K. Health behaviours, wellness, and multiple sclerosis amid COVID-19. Arch. Phys. Med. Rehabil. 2020, 101, 1839-1841. [CrossRef]

8. Morris-Bankole, H.; Ho, A. The COVID-19 pandemic experience in multiple sclerosis: The good, the bad and the neutral. Neurol. Ther. 2021, 10, 279-291. [CrossRef] [PubMed]

9. Pettinichio, D.; Maroto, M.; Chai, L.; Lukk, M. Findings from an online survey on the mental health effects of COVID-19 on Canadians with disabilities and chronic health conditions. Disabil. Health J. 2021, 14. [CrossRef]

10. Winkelmann, A.; Loebermann, M.; Reisinger, E.C.; Hartung, H.P.; Zettl, U.K. Disease-modifying therapies and infectious risks in multiple sclerosis. Nat. Rev. Neurol. 2016, 12, 217-233. [CrossRef] [PubMed]

11. Chaudhry, F.; Jageka, C.; Levy, P.D.; Cerghet, M.; Lisak, R.P. Review of the COVID-19 Risk in Multiple Sclerosis. J. Cell. Immunol. 2021, 3, 68-77. [CrossRef] [PubMed]

12. Zabalza, A.; Cárdenas-Robledo, S.; Tagliani, P.; Arrambide, G.; Otero-Romero, S.; Carbonell-Mirabent, P.; Rodriguez-Barranco, M.; Rodríguez-Acevedo, B.; Restrepo Vera, J.L.; Resina-Salles, M.; et al. COVID-19 in multiple sclerosis patients: Susceptibility, severity risk factors and serological response. Eur. J. Neurol. 2021, 28, 3384-3395. [CrossRef] [PubMed]

13. Motolese, F.; Rossi, M.; Albergo, G.; Stelitano, D.; Villanova, M.; Di Lazzaro, V.; Capone, F. The psychological impact of COVID-19 pandemic on people with multiple sclerosis. Front. Neurol. 2020, 11, 580507. [CrossRef] [PubMed] 
14. Garjani, A.; Hunter, R.; Law, G.R.; Middleton, R.M.; Tuite-Dalton, K.A.; Dobson, R.; Ford, D.V.; Hughes, S.; Pearson, O.R.; Rog, D.; et al. Mental health of people with multiple sclerosis during the COVID-19 outbreak: A prospective cohort and cross-sectional case-control study of the UK MS Register. Mult. Scler. J. 2021. [CrossRef] [PubMed]

15. Alnajashi, H.; Jabbad, R. Behavioral practices of patients with multiple sclerosis during COVID-19 pandemic. PLoS ONE 2020, 15, e0241103. [CrossRef] [PubMed]

16. Learmonth, Y.C.; Rice, I.M.; Ostler, T.; Rice, L.A.; Motl, R.W. Perspectives on physical activity among people with multiple sclerosis who are wheelchair users: Informing the design of future interventions. Int. J. MS Care 2015, 17, 109-119. [CrossRef] [PubMed]

17. Dalgas, U.; Langeskov-Christensen, M.; Stenager, E.; Riemenschneider, M.; Hvid, L.G. Exercise as medicine in multiple sclerosisTime for a paradigm shift: Preventive, symptomatic, and disease-modifying aspects and perspectives. Curr. Neurol. Neurosci. Rep. 2019, 19, 88. [CrossRef] [PubMed]

18. Motl, R.W.; Pilutti, L.A. The benefits of exercise training in multiple sclerosis. Nat. Rev. Neurol. 2012, 8, 487-497. [CrossRef]

19. Learmonth, Y.; Motl, R. Physical activity and exercise training in multiple sclerosis: A review and content analysis of qualitative research identifying perceived determinants and consequences. Disabil. Rehabil. 2016, 38, 1227-1242. [CrossRef] [PubMed]

20. Vanner, E.A.; Block, P.; Christodoulou, C.C.; Horowitz, B.P.; Krupp, L.B. Pilot study exploring quality of life and barriers to leisure-time physical activity in persons with moderate to severe multiple sclerosis. Disabil. Health J. 2008, 1, 58-65. [CrossRef] [PubMed]

21. Kayes, N.M.; McPherson, K.M.; Schluter, P.; Taylor, D.; Leete, M.; Kolt, G.S. Exploring the facilitators and barriers to engagement in physical activity for people with multiple sclerosis. Disabil. Rehabil. 2011, 33, 1043-1053. [CrossRef] [PubMed]

22. McLeroy, K.R.; Bibeau, D.; Steckler, A.; Glanz, K. An ecological perspective on health promotion programs. Health Educ. Q. 1998, 15, 351-377. [CrossRef] [PubMed]

23. Giles-Corti, B.; Donovan, R.J. The relative influence of individual, social and physical environment determinants of physical activity. Soc. Sci. Med. 2002, 54, 1793-1812. [CrossRef]

24. Sallis, J.F.; Cervero, R.B.; Ascher, W.; Henderson, K.A.; Kraft, M.K.; Kerr, J. An ecological approach to creating active living communities. Annu. Rev. Public Health 2006, 27, 297-322. [CrossRef] [PubMed]

25. Silveira, S.L.; Motl, R.W. Environmental correlates of health-promoting leisure physical activity in persons with multiple sclerosis using a social cognitive perspective embedded within social ecological model. Prev. Med. Rep. 2019, 15, 100921. [CrossRef] [PubMed]

26. Motl, R.W.; McAuley, E.; Snook, E.M. Physical activity and multiple sclerosis: A meta-analysis. Mult. Scler. 2005, 11, 459-463. [CrossRef]

27. Bonnell, K.; Michalovic, E.; Koch, J.; Pagé, V.; Ramsay, J.; Gainforth, H.L.; Lamontagne, M.E.; Sweet, S.N. Physical activity for individuals living with a physical disability in Quebec: Issues and opportunities of access. Disabil. Health J. 2021, 14, 101089. [CrossRef]

28. Government of Canada. Community-Based Measures to Mitigate the Spread of Coronavirus Disease (COVID-19) in Canada. 2021. Available online: https://www.canada.ca/en/public-health/services/diseases/2019-novel-coronavirus-infection/healthprofessionals / public-health-measures-mitigate-covid-19.html (accessed on 29 November 2021).

29. Block, V.J.; Bove, R.; Gelfand, J.M.; Cree, B.A. Effects of COVID-19 "Sheltering in Place" on activity in people with multiple sclerosis. Neurol. Clin. Pract. 2020. [CrossRef] [PubMed]

30. Kalron, A.; Dolev, M.; Greenber-Abrahami, M.; Menascu, S.; Frid, L.; Avrech-Shezifi, S.; Harari, G.; Magalashvili, D.; Achiron, A. Physical activity behaviour in people with multiple sclerosis during the COVID-19 pandemic in Israel: Results of an online survey. Mult. Scler. Relat. Disord. 2020, 47, 102603. [CrossRef] [PubMed]

31. Okoro, C.A.; Strine, T.W.; McKnight, L.; Verlenden, J.; Hollis, N.D. Indicators of poor mental health and stressors during the COVID-19 pandemic, by disability status: A cross-sectional analysis. Disabil. Health J. 2021, 101110. [CrossRef] [PubMed]

32. Teti, M.; Schatz, E.; Liebenberg, L. Methods in the time of COVID-19: The vital role of qualitative inquiries. Int. J. Qual. Methods 2020, 19, 19. [CrossRef]

33. Palinkas, L.A.; Horwitz, S.M.; Green, C.A.; Wisdom, J.P.; Duan, N.; Hoagwood, K. Purposeful sampling for qualitative data collection and analysis in mixed method implementation research. Adm. Policy Ment. Health 2015, 42, 533-544. [CrossRef] [PubMed]

34. Braun, V.; Clarke, V. Using thematic analysis in psychology. Qual. Res. Psychol. 2006, 3, 77-101. [CrossRef]

35. Braun, V.; Clarke, V. Reflecting on reflexive thematic analysis. Qual. Res. Sport Exerc. Health 2019, 11, 589-597. [CrossRef]

36. Braun, V.; Clarke, V.; Weate, P. Using thematic analysis in sport and exercise research. In Routledge Handbook of Qualitative Research in Sport and Exercise; Routledge: London, UK, 2016; pp. 213-227.

37. Braun, V.; Clarke, V. One size fits all? What counts as quality practice in (reflexive) thematic analysis? Qual. Res. Psychol. 2020, 18, 328-352. [CrossRef]

38. Smith, B.; McGannon, K. Developing rigor in qualitative research: Problems and opportunities within sport and exercise psychology. Int. Rev. Sport Exerc. Psychol. 2018. [CrossRef]

39. Pietrabissa, G.; Simpson, S.G. Psychological consequences of social isolation during COVID-19 outbreak. Front. Psychol. 2020, 11, 2201. [CrossRef] 
40. Freeman, J.; Gorst, T.; Gunn, H.; Robens, S. "A non-person to the rest of the world": Experiences of social isolation amongst severely impaired people with multiple sclerosis. Disabil. Rehabil. 2020, 42, 2295-2303. [CrossRef]

41. Cattaneo, D.; Lamers, I.; Bertoni, R.; Feys, P.; Jonsdottir, J. Participation Restriction in People with Multiple Sclerosis: Prevalence and Correlations With Cognitive, Walking, Balance, and Upper Limb Impairments. Arch. Phys. Med. Rehabil. 2017, 98, 1308-1315. [CrossRef]

42. Dalise, S.; Tramonti, F.; Armienti, E.; Niccolini, V.; Caniglia-Tenaglia, M.; Morganti, R.; Chisari, C. Psycho-social impact of social distancing and isolation due to the COVID-19 containment measures on patients with physical disabilities. Eur. J. Phys. Rehabil. Med. 2021, 57, 158-165. [CrossRef]

43. Marck, C.H.; Hunter, A.; Heritage, B.; Gibbs, L.; Kermode, A.G.; Walker, D.I.; Learmonth, Y.C. The effect of the Australian bushfires and the COVID-19 pandemic on health behaviours in people with multiple sclerosis. Mult. Scler. Relat. Disord. 2021, 53, 103042. [CrossRef]

44. Tallner, A.; Pfeifer, K.; Mäurer, M. Web-based interventions in multiple sclerosis: The potential of tele-rehabilitation. Ther. Adv. Neurol. Disord. 2016, 9, 327-335. [CrossRef]

45. Learmonth, Y.; Marshall-McKenna, R.; Paul, L.; Mattison, P.; Miller, L. A qualitative exploration of the impact of a 12-week group exercise class for those moderately affected with multiple sclerosis. Disabil. Rehabil. 2013, 35, 81-88. [CrossRef]

46. Backus, D. Increasing physical activity and participation in people with multiple sclerosis: A review. Arch. Phys. Med. Rehabil. 2016, 97, S210-S217. [CrossRef]

47. Learmonth, Y.C.; Chan, Z.; Correia, H.; Hathorn, D.; Kermode, A.; Smith, C.; Walker, D. Exercise participation and promotion in the multiple sclerosis community; perspectives across varying socio-ecological levels. Disabil. Rehabil. 2021, 43, $3623-3638$. [CrossRef] 